\title{
NARRATIVAS VIVENCIALES A TRAVÉS DE LA FOTOGRAFÍA CON LA COMUNIDAD LGBT EN SAN JUAN DE PASTO
}

\section{Entorno Cultura}

\author{
Laura Alejandra Realpe Lara \\ laura.realpe28@gmail.com \\ Universidad CESMAG \\ Pasto, Nariño.
}




\section{Resumen}

En Colombia, la comunidad de Lesbianas, Gays, Bisexuales, Transgénero y Transexuales - (LGBT) ha logrado conseguir algunos derechos; pero, aún se evidencia discriminación, desigualdad y violencia, debido a la hegemonía de una visión social, la homofobia, transfobia, machismo, prejuicios morales, creencias conservadoras, tradicionalismos, religiones timoratas que han ocasionado diversas consecuencias a las personas pertenecientes a dicha comunidad, con consecuencias de opresión, ocultamiento o juzgamiento equivocado, por lo que estas personas temen revelar su orientación sexual o su identidad de género. Se trazaron dos objetivos: i) Construir una narrativa visual por medio de la fotografía de retrato, que represente y refleje los sucesos de vida de jóvenes y adultos LGBT, participantes que son amigos, compañeros y personas con alguna relación, con el fin de transmitir sus historias de vida y mensajes; ii) Realizar una exposición fotográfica en San Juan de Pasto, como un espacio de impacto social, para que el espectador conozca las historias de vida, los retratos y comprenda la diversidad en orientación sexual, género, identidad y expresión de género. Como metodología se acogió el enfoque de Investigación Acción Participación (IAP) y el Design Thinking. Las herramientas para la recolección de información fueron la observación participante y grupo focal. La muestra la conformaron 5 personas, con edades entre 18 a 35 años, pertenecientes a la comunidad LGBTQ. Como conclusión se tiene que la exposición fotográfica se emplea como herramienta que genera impacto social, ya que evidencia las consecuencias de una sociedad con prejuicios ante los retratos de los y las participantes.

\section{Introducción}

La libertad para desarrollar la personalidad y vivir plenamente es un derecho y deber en la sociedad. Además de esto, debe ser respetada y promovida por la comunidad, en tanto esta no dañe la integridad ni vulnere la libertad de la otra u otros. Por lo tanto, el género y la sexualidad se encuentran implicadas en el desarrollo personal, y cada país debe garantizarlo. En Colombia se observa una desventaja en el reconocimiento de la comunidad de Lesbianas, Gays, Bisexuales, Transgénero, Transexuales y Travestis (LGBTQ); no obstante, durante la lucha por sus derechos, han logrado conquistar algunos que ya tienen las personas heteronormativas. Sin embargo, luchar por ellos demuestra la desigualdad y discriminación que sufren, donde, por ser una comunidad poco numerosa, los prejuicios y violencia contra ella ocasionan su opresión, ocultamiento y juzgamiento (Ministerio de Educación Nacional y Fondo de Población de las Naciones Unidas, 2016).

Así entonces, en Colombia tener una orientación sexual o identidad de género que no sea la normativa, es sujeto de violencia, asesinato o rechazo social, como lo reportan los 405 casos registrado por discriminación, homicidios, violencia policial y víctimas del conflicto armado, desde el 2012 hasta el 2015 (Colombia Diversa, Santa María y Caribe Afirmativo, 2015). Son manifestaciones que muestran que en Colombia la discriminación y la homofobia aún son latentes y alarmantes, que no sólo se ve reflejada por parte de los padres o comunidad sino, también, en instituciones educativas, gubernamentales y otras (El Espectador, 2017). Como consecuencia, muchas personas temen revelar su orientación sexual e identidad 
de género por cuestiones religiosas y fuertes lazos familiares, como sucede en la ciudad de Pasto. La investigación, entonces, busca compartir historias de vida a través de la fotografía de retrato (Giordano \& Méndez, 2001; Abraham, 2015), historias de personas que han luchado para construir con libertad su orientación sexual o identidad de género al interior de una sociedad homofóbica, transfóbica y hegemónica.

Retratos íntimos, encuentros con amigos personales, familia, extraños que se vuelven amigos, retratados en sus dormitorios o lugares íntimos, donde pueden ser ellos mismos sin prejuicios sociales. Ellos deciden cómo desean ser retratados y qué fragmentos de sus historias desean compartir, para buscar, así, visibilizar a su comunidad a partir de sus historias, brindar un apoyo a personas LGBTQ, al manifestar que no están solas o solos, porque también han vivido lo mismo. Uno de los objetivos de la investigación, es socializar el resultado mediante una exposición fotográfica en la ciudad de Pasto, para generar un aporte a la lucha colectiva y las transformaciones sociales y personales.

\section{Metodología}

El enfoque del estudio fue la Investigación Acción Participativa (IAP), el cual integra la investigación, la acción social y la participación activa de los participantes en el proceso investigativo y de intervención, para construir el conocimiento colectivo con la fundamentación teórica-práctica y la intersubjetividad (López \& Scandroglio, 2007). Como diseño y herramienta en la intervención, la participación activa de las personas de la comunidad LGBTQ participaron tomando decisiones, contando sus historias, decidiendo en las fotografías y apropiándose del proceso que se realizó.

Mientras que para la ejecución de la producción y desarrollo del proceso creativo se realizaron desde la perspectiva del Design Thinking, donde las etapas aportaron al desarrollo del proyecto, con una situación problemática como un todo (emoción, cognitivo y estético), en el contexto que afecta el bienestar de la vida de las personas; por ello, se deben situar en el centro del proceso, en este caso, a las personas pertenecientes a la comunidad LGBTQ (Maluenda \& Dubó, 2018).

Como herramientas para la recolección de la información, se acogieron la observación participativa y el grupo focal.

La muestra de participantes la conformaron 5 personas, con edades entre 18 a 35 años, de diferentes estratos socioeconómicos, nivel educativo, pertenecientes a la comunidad LGBTQ, que tengan una relación cercana con la persona que realiza la investigación. 


\section{Resultados}

El proyecto se encuentra en curso, por lo que se tienen resultados parciales de la realización de los retratos con los participantes y de la exposición fotográfica realizada en la ciudad de Pasto. En cuanto a las sesiones fotográficas, se retrató a cinco personas que estuvieron dispuestas a compartir sus historias sobre su orientación sexual o identidad de género, quienes permitieron un encuentro íntimo en el ambiente en donde viven, para tomar, así, un fragmento de sus vidas y sentimientos a través de la fotografía.

En la redacción de los relatos, el objetivo es que ellos escriban lo que deseen, llegando a variar entre participantes que escriben para sus seres queridos hasta pequeños fragmentos de sus historias de vida. En el encuentro de la escucha de las historias, se conoce más de ellos, al conmover e invitar a conocer más sobre ellos, abrir y dar la oportunidad de manifestarse y expresar sus deseos, además de cómo desearían y quieren relacionarse, ser tratados y ser vistos por las demás personas.

La primera historia es la de Danilo (véase figura 1), un chico de Brasil que actualmente reside en Pasto por un intercambio interuniversitario. Danilo comparte un escrito en el que cuenta todo el proceso que él vivió antes de manifestarle a su familia sobre su orientación sexual, cuenta que vivió mucho tiempo reprimiendo lo que él era realmente, para encajar en la sociedad hegemónica.

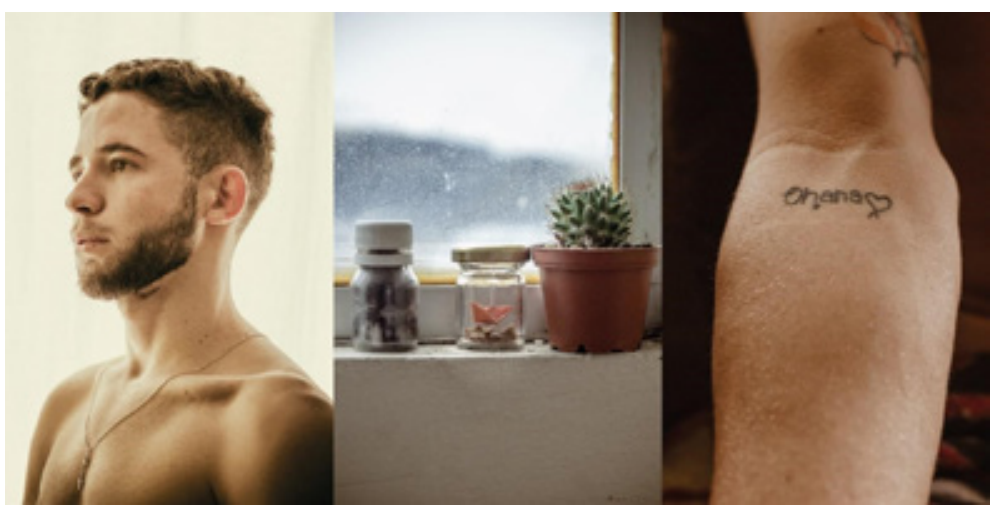

Figura 1. Retrato de Danilo Fuente: Archivo fotográfico del autor

Se cita un apartado del relato escrito por Danilo, que evidencia la situación que vivió con su familia:

De todos los niños de mi clase, yo era el que tenía la letra más bella (...) Ahí me descubrieron, tuve que esconder un secreto. Traté de cambiar mi voz, mi forma, mis gestos. Intenté en todos los sentidos evitar que la flor que nació conmigo creciera frondosa, me convertí en alguien introvertido y asustado. Si hubiera estado orgulloso de mi letra, no habría escuchado un cierto sermón sobre los diferentes. Nadie más que yo tiene el control de mi felicidad, y creo que es menos agotador tratar de ser feliz que perfecto. Finalmente, diré que te amo mamá. 
La segunda historia es la de Diego (véase figura 2), la persona con quien, como menciona la investigadora, "yo he compartido toda mi vida con él”, se ha retratado desde hace más de cuatro años. Diego vive con libertad su orientación sexual y su amor con un chico, quienes comparten una relación estable. Durante el proceso de realización de la fotografía y al compartir más su vida, permitió que en estos espacios se conociera más cosas sobre él, su proceso y crecimiento personal.

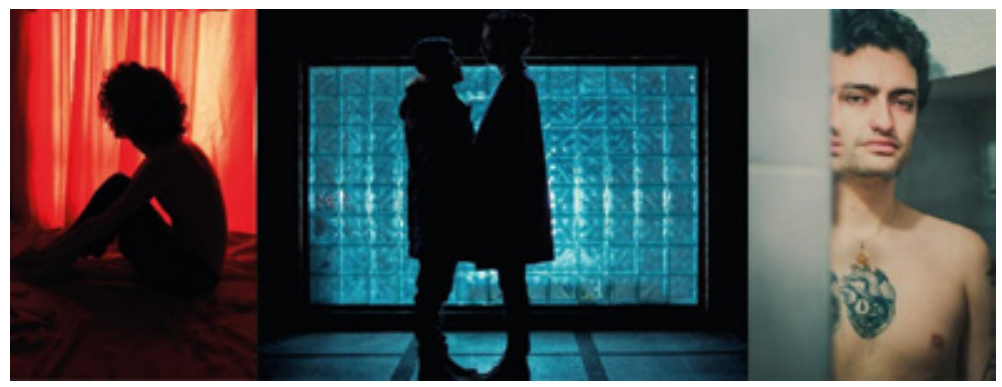

Figura 2. Retrato de Diego Fuente: Archivo fotográfico del autor

Se observa, principalmente, en este párrafo de su carta, sobre la importancia que tuvo para él, aceptar y encontrar el amor e identidad y, “A veces, en el proceso de descubrir bien quién eres te pierdes un poco, no sabes bien qué hacer, te sientes solo y en las sombras, pero luego encuentras apoyo y compañía y eso hace todo el proceso más llevadero".

La tercera historia es la de Jorge (véase figura 3), quien decide escribir algo para su abuela y agradecerle por su apoyo en todo su desarrollo.

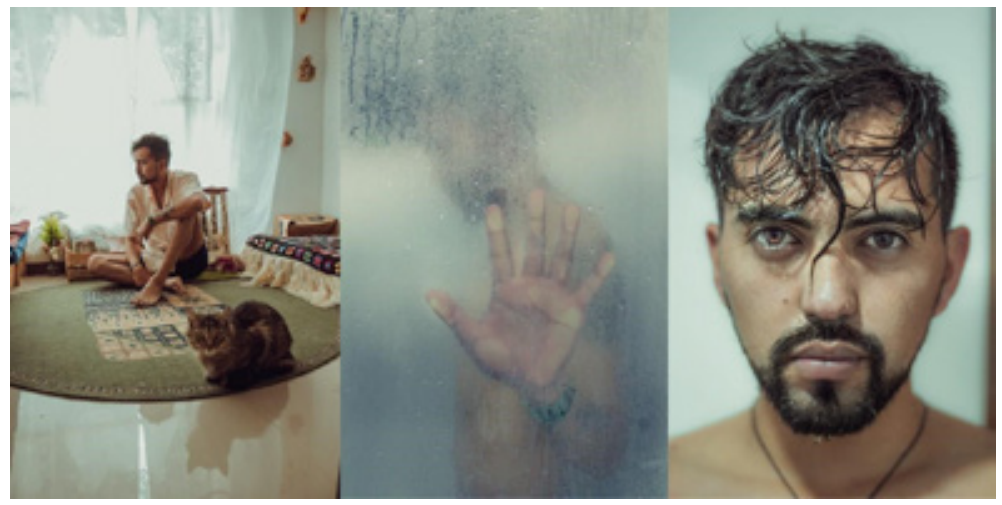

Figura 3. Retrato de Jorge Fuente: Archivo fotográfico del autor

El siguiente es un aparte de la carta de Jorge, dirigida a su abuela:

Abuela a tres años de tu partida. Aún no me acostumbro me haces falta en momentos de mi vida que han sido cruciales para mi desarrollo, tengo claro que todas las enseñanzas que me diste me han servido para salir adelante. No me he dejado caer y he sido constante. Tu amor viejito será eterno en mi alma. 
La cuarta historia es la de Valentina (véase figura 4), una mujer trans que, actualmente, está iniciando su proceso de transición. Ella cuenta que, por miedo a una reacción negativa de su madre, tuvo que reprimir por mucho tiempo aquello que sentía en su proceso de reconocimiento como una mujer. Cuenta que cada día está logrando ser lo que ella desea y, gracias a esto, se siente segura de sí misma.

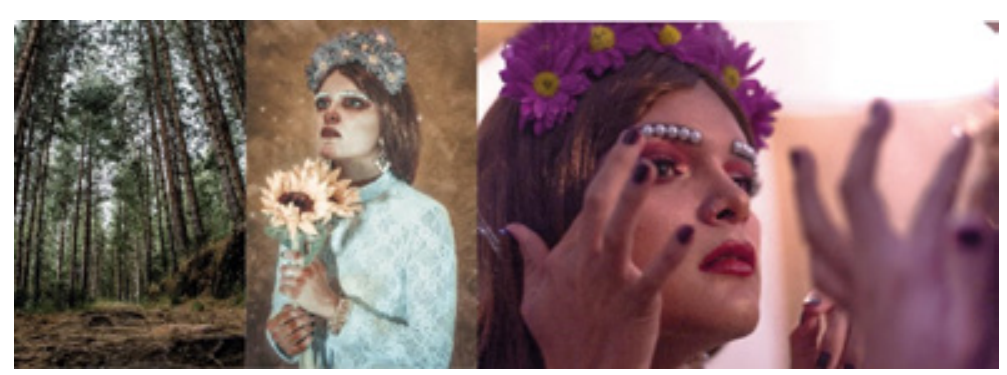

Figura 4. Retrato de Valentina

Fuente: Archivo fotográfico del autor

Valentina relata en su carta, parte de sus vivencias:

Salí del closet dos veces, la primera fue cuando dije que era gay, lo dije porque desconocía el tema de personas trans, me sentía inconforme conmigo misma y comencé a buscar respuestas. No es fácil sentir lo que sentí por muchos años, esa inconformidad al verme en el espejo. Hoy me siento orgullosa de mí, porque estoy logrando ser cada día en quien me gustaría ser, soy una mujer y me siento segura de lo que soy.

La quinta historia es de Bianda (véase figura 5); ella tiene una relación complicada con su madre, porque no acepta su orientación sexual, cuenta que ella encontró el amor con otra mujer y que, gracias a su relación, Bianda decide experimentar y arriesgarse, a pesar de que su madre no la apoye.

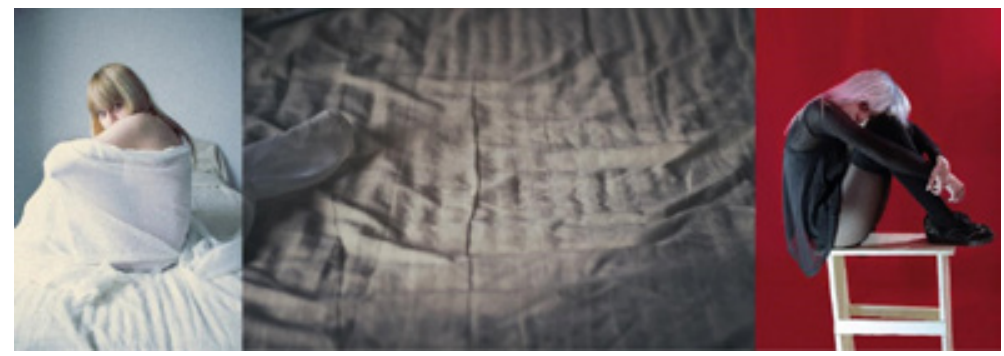

Figura 5. Retrato de Bianda

Fuente: Archivo

fotográfico del autor

En el relato de Bianda, se puede apreciar la relación con su familia:

Yo no puedo culpar a mi mamá por no entender mi amor. Aunque a mí me tomó mucho tiempo reconocerlo y aceptarlo. Como humanos siempre estamos en búsqueda de construir con los demás. Yo elegí un amor para construir con ella magia y futuro, con ella escogí experimentar y aventurarme con mis pensamientos y sentimientos. 
Finalmente, dos historias se presentaron en la exhibición fotográfica Tránsitos de luz, una muestra que fue el resultado del taller de Narrativas visuales en Pasto, con la curaduría de Edith G. Coka. Se tuvo una buena reacción del público, ya sea por la estética que se utiliza en cada una de las fotos, por las personas que aparecen retratadas, y por las cartas y relatos que están contando la realidad y experiencia de los participantes. Algunos asistentes generaron la reflexión y comentaron sobre la importancia de hablar sobre estos temas y retratar situaciones problemáticas, que aún generan impacto en la sociedad y en la vida de las personas que están sumergidas en ella. En la exhibición, los asistentes llegaron a la conclusión de que es necesarios retratar más problemáticas, puesto que en la Ciudad, los trabajos fotográficos que más se caracterizan, se relacionan con paisaje, patrimonio o retratos a comunidades; pero, nadie se atreve a tratar ni exponer temas relacionados con la comunidad LGBTQ en Pasto.

Algunas asistentes comentaron lo importante que es hablar y retratar estos temas, que aún generan impacto en la sociedad, y que son necesarios de retratar, puesto que en la Ciudad, los trabajos fotográficos que más se realizan son en relación con el paisaje, fotografía patrimonial o retratos a comunidades, pero nadie se atreve a tratar temas relacionados a la comunidad LGBT.

Se trató de trabajar con herramientas que no resultaran costosas y se tengan en la mano, para demostrar que no es necesario tener grandes equipos fotográficos y de iluminación, para lograr buenos resultados. La estética de las fotografías generó curiosidad en los espectadores.

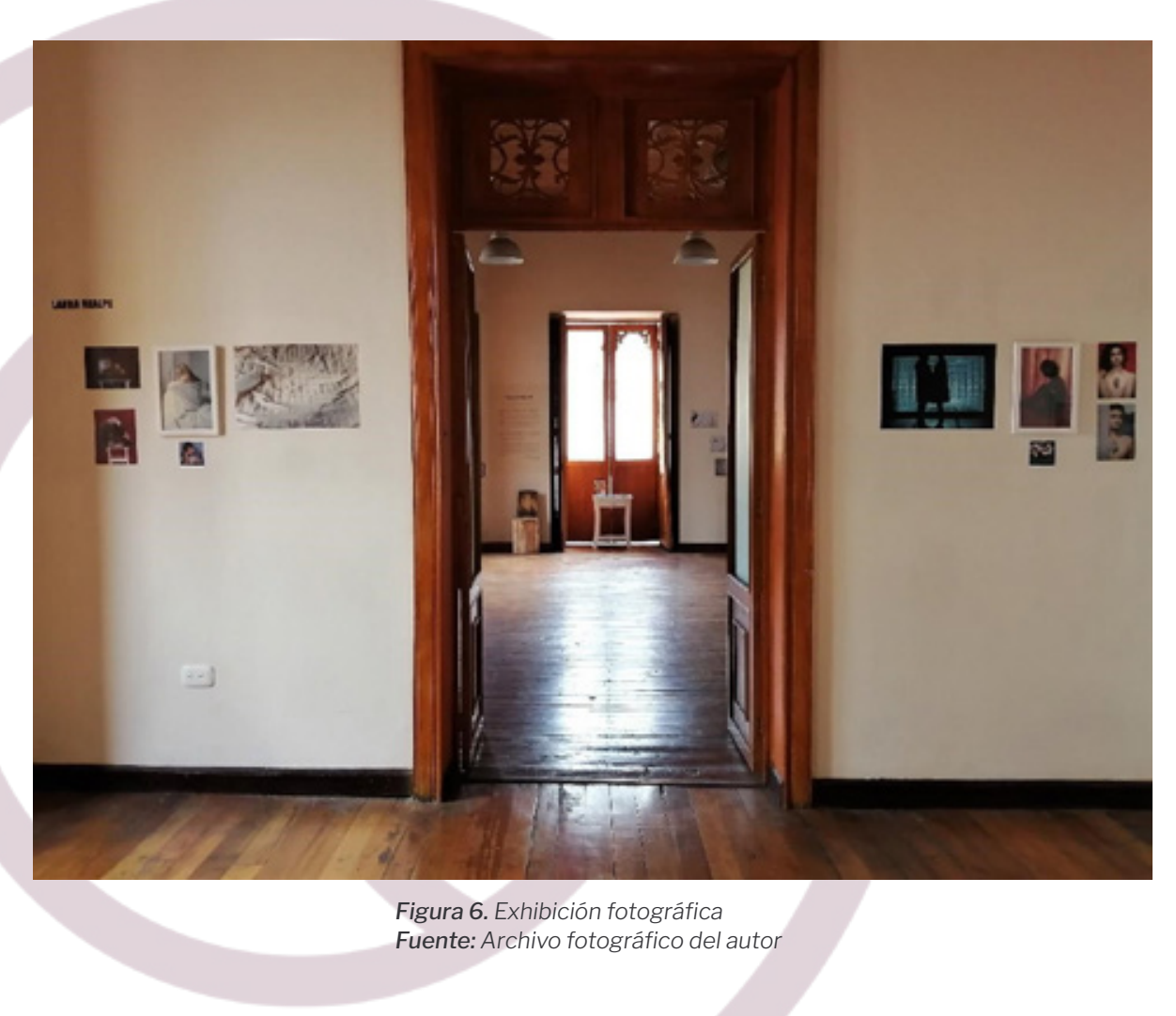


Como resultado del Design Thinking, se evidenció que por medio de la empatía, la comprensión y la relación con los participantes, favoreció el proceso creativo. Se enfocó en cada uno, el retrato como producto desde su centro, con las ideas generadas y las emociones que produce cada una de las fotografías en ellos. Se presentó, no solamente un retrato de una situación problemática sino, también, emociones, momentos, recuerdos y una lucha por la libertad, el amor personal y la felicidad.

\section{Conclusión}

La exposición fotográfica se emplea como herramienta que genera impacto social, ya que evidencia ciertas consecuencias de la sociedad que aún forma prejuicios, extremista y conservadora ante los retratos de los y las participantes. Cada historia intenta transmitir sus vivencias y sentimientos a los asistentes de la exposición, para buscar una reflexión y reacción en ellos y ellas, que aporte al cambio social al sensibilizar estas situaciones que se presentan. La exposición fotográfica invita a generar una reflexión y entender las diferencias.

\section{Referencias}

Abraham, L. (26 de agosto de 2015). Breve historia de la fotografía construida [Mensaje en página web Yaconic]. Recuperado de https://www.yaconic.com/breve-historia-de-lafotografia-construida/

Colombia Diversa, Caribe Afirmativo y Santamaría Fundación. (2015). Cuerpos excluidos, rostros de impunidad. Informe de violencia hacia personas LGBT en Colombia, 2015. Recuperado de http://colombiadiversa.org/ddhh-lgbt/Informe-Violencia-LGBTColombia-DDHH-2015.pdf

El Espectador, Redacción. (27 de octubre de 2017). Segunda condena en caso Sergio Urrego: Psicóloga fue sentenciada a 35 meses de prisión. El Espectador. Recuperado de https://www.elespectador.com/noticias/bogota/segunda-condena-en-caso-sergiourrego-psicologa-fue-sentenciada-35-meses-de-prision-articulo-711455

Giordano, M. \& Méndez, P. (2001). El retrato fotográfico en Latinoamérica: testimonio de una identidad. Tiempos de América, 8, 121-135. Recuperado de https://www.raco. cat/index.php/TiemposAmerica/article/view/105132/163905

López, J. \& Scandroglio, B. (2007). De la investigación a la intervención psicosocial: la metodología cualitativa y su integración con la metodología cuantitativa. En A. Blanco \& J. Rodríguez (Coords.), Intervención Psicosocial (pp. 575-577). Madrid: Pearson Educación.

Maluenda, J. \& Dubó, S. (2018). Estrategia metodológica para enseñar innovación en estudiantes de cinesiología. Fem, 21(5), 235-237. Recuperado de http://scielo.isciii. es/pdf/fem/v21n5/2014-9832-fem-21-5-235.pdf

Ministerio de Educación Nacional de Colombia y Fondo de Población de las Naciones Unidas. (2016). Ambientes escolares libres de discriminación. Orientaciones sexuales e identidades de género no hegemónicas en la escuela. Aspectos para la reflexión. Recuperado de https://unicef.org.co/sites/default/files/informes/Ambientes\%20 escolares\%20Libres\%20de\%20Discriminacion\%20May\%202016_0.pdf 